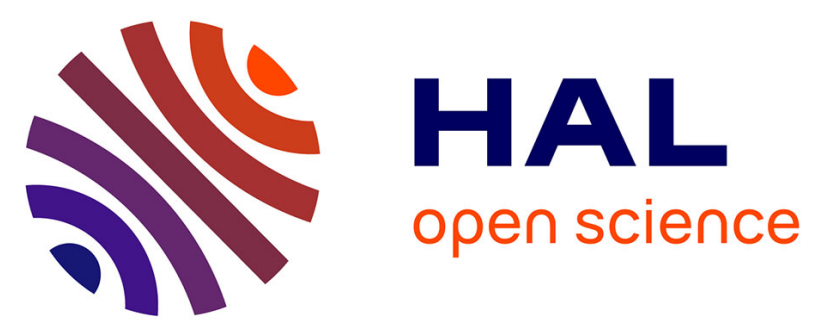

\title{
Organometallic chemistry of new carbon materials. Structure and dynamic behavior of group 6 metal tricabonyl complexes of graphene and perforated graphene: a DFT study
}

N. S. Zhulyaev, I. P. Gloriozov, M. S. Nechaev, F. Gam, Yu. F. Oprunenko, Jean-Yves Saillard

\section{To cite this version:}

N. S. Zhulyaev, I. P. Gloriozov, M. S. Nechaev, F. Gam, Yu. F. Oprunenko, et al.. Organometallic chemistry of new carbon materials. Structure and dynamic behavior of group 6 metal tricabonyl complexes of graphene and perforated graphene: a DFT study. New Journal of Chemistry, 2019, 43 (46), pp.17991-18002. 10.1039/c9nj02187f . hal-02438561

\section{HAL Id: hal-02438561}

\section{https://hal-univ-rennes1.archives-ouvertes.fr/hal-02438561}

Submitted on 11 Feb 2020

HAL is a multi-disciplinary open access archive for the deposit and dissemination of scientific research documents, whether they are published or not. The documents may come from teaching and research institutions in France or abroad, or from public or private research centers.
L'archive ouverte pluridisciplinaire HAL, est destinée au dépôt et à la diffusion de documents scientifiques de niveau recherche, publiés ou non, émanant des établissements d'enseignement et de recherche français ou étrangers, des laboratoires publics ou privés. 


\title{
Organometallic Chemistry of New Carbon Materials IV. Structure and Dynamic Behavior of Group 6 Metal Tricabonyl Complexes of Graphene and Perforated Graphene: A DFT Study
}

N. S. Zhulyaev, ${ }^{a}$ I. P. Gloriozov, ${ }^{a}$ M. S. Nechaev, ${ }^{a, b}$ F. Gam, ${ }^{c}$ Yu. F. Oprunenko, *a J.-Y. Saillard ${ }^{c}$

${ }^{a}$ Department of Chemistry, M. V. Lomonosov Moscow State University, Building 3, Vorob'evy Gory, 119992 Moscow, Russia.

Fax and phone: +7 (495) 939 2677, E-mail: oprunenko@org.chem.msu.ru

${ }^{b}$ A. V. Topchiev Insitute of Petrochemical Synthesis, Russian Academy of Sciences, Leninsky Prospect 29, 119991 Moscow, Russia.

${ }^{c}$ Univ Rennes, CNRS, ISCR - UMR 6226, F-35000 Rennes, France.

Fax and phone: 33 (0)2 232367 28,E-mail: saillard@univ-rennes1.fr

\begin{abstract}
The mechanism of inter-ring haptotropic rearrangements (IRHR) was investigated by DFT for tricarbonyl $\eta^{6}$-complexes of group 6 metals $(\mathrm{M}=\mathrm{Cr}, \mathrm{Mo}, \mathrm{W})$ of coronene (I-M), kekulene (II-M) and a model graphene (III-M). The computed $\eta^{6}, \eta^{6}$-IRHR activation barriers in the middle size PAHs I-M, and II-M were calculated to be substantially lower than in the case of complexes of relatively small size PAHs such as naphthalene chromium tricarbonyl $\left(\Delta G^{\#} \approx 20\right.$ $25 \mathrm{kcal} \mathrm{mol}^{-1}$ vs. $\approx 30 \mathrm{kcal} \mathrm{mol}^{-1}$ ). The barrier is further lowered in the case of the model graphene complex III-Cr $\left(\Delta G^{\#} \approx 13 \mathrm{kcal} \mathrm{mol}^{-1}\right)$. An even lower barrier is found for III-Mo $\left(\Delta G^{\#}\right.$ $\left.\approx 10 \mathrm{kcal} \mathrm{mol}^{-1}\right)$, whereas it slightly increases for III-W $\left(\Delta G^{\#} \approx 14 \mathrm{kcal} \mathrm{mol}^{-1}\right)$.
\end{abstract}

Keywords: density functional theory, metal tricarbonyl complexes, PAHs, graphene, interring haptotropic rearrangements. 


\section{Introduction}

Transition metal complexes of polycyclic aromatic hydrocarbons (PAHs) are of considerable interest due to their structural peculiarities and dynamic properties. ${ }^{1}$ Their ability to catalyze various organic reactions provide them with many practical applications. ${ }^{2}$ They are also widely used for the activation of specific positions in the coordinated PAH ring. This approach facilitates the preparation of synthetically important organic derivatives from aromatic ligands. This includes industrial production of optically pure substances of pharmaceutical utility. ${ }^{3-5} \mathrm{PAH}$ transition metal complexes are characterized by variable fluxional behavior. Inter-ring haptotropic rearrangements (IRHRs) $\left(\eta^{\mathrm{n}}, \eta^{\mathrm{n}}\right.$-IRHR, $\left.n=2,4,6\right)$ were among the most actively studied molecular dynamic processes in the recent years. These transformations consist of the migration of an $\mathrm{ML}_{n}$ organometallic group (OMG) along the PAH molecule from one sixmembered ring to another one, ${ }^{\mathbf{6 - 8}}$ as illustrated in Scheme 1 in the case of naphthalene.

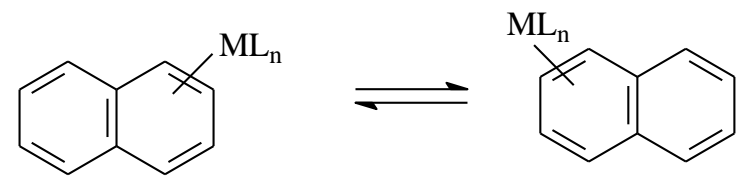

Scheme 1

The most extensively studied energy barrier associated with such IRHR processes corresponds to R-substituted $\eta^{6}$-chromium tricarbonyl complexes $\left(\eta^{6}, \eta^{6}\right.$-IRHR). In this case, the chromium tricarbonyl group migrates along the polyaromatic carbo- ${ }^{6,7}$ or hetero-cycle ${ }^{8}$ (Scheme 2).
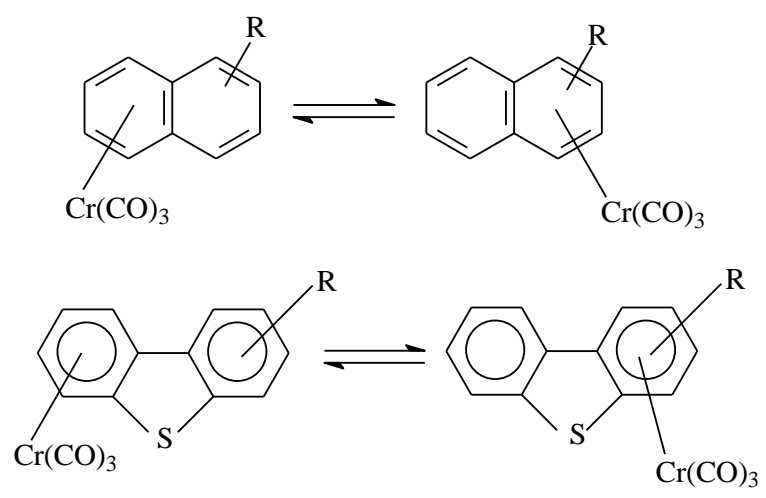

$\mathrm{R}=\mathrm{Me}, \mathrm{D}, \mathrm{SiMe}_{3}, \mathrm{SnMe}_{3}$

Scheme 2 
The experimental thermodynamic parameters of these $\eta^{6}, \eta^{6}$-IRHR obtained on the basis of kinetic data are in the range of $\Delta G^{\#} \sim 27-33 \mathrm{kcal} \mathrm{mol}^{-1}$. They occur at temperatures around 90$130^{\circ} \mathrm{C}$ in inert non-coordinating solvents (e.g. decane, decaline, hexafluorobenzene). They are determined on $\pi$-complexes containing one $\mathrm{R}$ group on the ligand, thus eliminating isomer degeneracy. The latter can be quantitatively determined in the reaction mixture mainly using the NMR method. 4,6-8 Factors such as the PAH and OMG natures and the presence of substituents or heteroatoms, exert a considerable effect on the direction and rate of the process. ${ }^{\mathbf{6}-12}$

Mechanistic density functional theory (DFT) investigations of these $\eta^{6}, \eta^{6}$-IRHRs have been previously performed by us, mainly for chromium tricarbonyl complexes of naphthalene, biphenyl, biphenylene, dibenzothiophene, carbazole, fluoranthene). ${ }^{\mathbf{1 0 , 1 1}}$ Chromium tricarbonyl complexes of anthracene, phenanthrene or pyrene have been investigated by other authors. ${ }^{\mathbf{1 2}}$ For such complexes of small PAHs, the calculated activation barriers $\Delta \mathrm{G}^{\#}$ were all of the order of 30 $\mathrm{kcal} \mathrm{mol}^{-1}$. DFT calculations have been also performed for large PAHs, i.e. graphene ${ }^{\mathbf{1 3}}$ and nanotubes. ${ }^{14}$ For all these $\pi$-complexes, DFT was able to reproduce not only the experimental structural parameters, but also their thermodynamic and $\eta^{6}, \eta^{6}$-IRHR kinetic data. ${ }^{10,11,15-18}$ In addition, DFT allows calculating spectral parameters at a reasonable accuracy $(\sim 10 \%)$, such as ${ }^{1} \mathrm{H}$ and ${ }^{13} \mathrm{C}$ NMR chemical shifts ${ }^{\mathbf{1 9 , 2 0}}$ as well as IR vibrational frequencies of carbonyl groups. ${ }^{\mathbf{2 1}}$ Such computed spectral parameters should facilitate compounds identification in the future.

Investigations of $\eta^{6}, \eta^{6}$-IRHRs for molybdenum complexes are much rarer. For example, experimental $^{\mathbf{2 2}}$ and theoretical ${ }^{\mathbf{2 3}}$ rearrangement studies in heterocyclic PAH complexes of $\mathrm{Mo}\left(\mathrm{POMe}_{3}\right)_{3}$ have been performed. As far as we know, $\eta^{6}, \eta^{6}$-IRHR activation barriers of tungsten complexes were neither experimentally nor theoretically studied, with the exception of a DFT investigation devoted to group 6 tricarbonyl complexes of exotic hydroxyl- and methoxysubstituted phenanthrenes. ${ }^{24}$ Thus, there are no studies that allow correct comparison of experimental and theoretical data with respect to the nature of the metal within the group 6 triad. Therefore, the dependence of the mechanisms and activation energies on the metal nature remains yet unclear. Thus, theoretical modeling of the structure and dynamic behavior of group 6 transition metals complexes of PAH appears to be an interesting and urgent task. Indeed, it is directly related to many aspects of practical use of these complexes in materials science, medicine, and catalysis. ${ }^{1-5}$

In the followings, we investigate the IRHR processes of $\mathrm{M}(\mathrm{CO})_{3}(\mathrm{M}=\mathrm{Cr}, \mathrm{Mo}, \mathrm{W})$ complexes of coronene ${ }^{25}$ I, kekulene ${ }^{26}$ II and the larger model III $\left(\mathrm{C}_{96} \mathrm{H}_{24}\right)$ (Fig. 1). These fairly large PAHs can be considered as reasonable models for graphene and imperfect (defected or perforated) graphenes, as well as various new carbon materials (NCMs). ${ }^{\mathbf{1 3 , 1 4}}$ Whereas group 6 complexes of $\mathbf{I}$ are unknown, their isoelectronic $\mathrm{FeCp}^{+}$and $\mathrm{RuCp}^{+}$counterparts were briefly 
decribed. ${ }^{27,28}$ On the other hand, no complex of II has been reported so far. With respect to high molecular weight PAHs such as NCMs like fullerenes, graphene, graphite, and nanotubes, there are some reports of the synthesis and characterization of chromium complexes. ${ }^{\text {29-31 }} \mathrm{The} \mathrm{Cr} / \mathrm{C}$ ratio in these polymetallic complexes varies in a wide range, the maximum value being $\mathrm{Cr} / \mathrm{C} \sim 1 / 18$. Not only $\eta^{6}$-molybdenum or $\eta^{6}$-tungsten tricarbonyl complexes of such NCMs are not documented so far, but even their complexes of small PAHs are poorly studied..$^{\mathbf{3 2}}$

Coordination of unligated $\mathrm{M}(0)$ group 6 metal atoms at the surface of NCMs and migration between six-membered rings have been investigated by electron microscopy. ${ }^{33-35}$ The $\mathrm{M}(0)$ migration has been shown to be very fast because of its weak bonding interaction with the ligand. Eventually, the $\mathrm{M}(0)$ atoms aggregate upon collisions to form less mobile clusters, mainly on the edges of the $\mathrm{NCM}^{35}$ On the other hand, although the unusually high rate of $\mathrm{Cr}(\mathrm{CO})_{3} \eta^{6}, \eta^{6}$-IRHR over a graphene surface was theoretically ${ }^{\mathbf{1 3}, \mathbf{1 4}}$ and experimentally proved, ${ }^{\mathbf{3 1}, 35}$ it is nevertheless slower than that of an $\mathrm{M}(0)$ atom. 


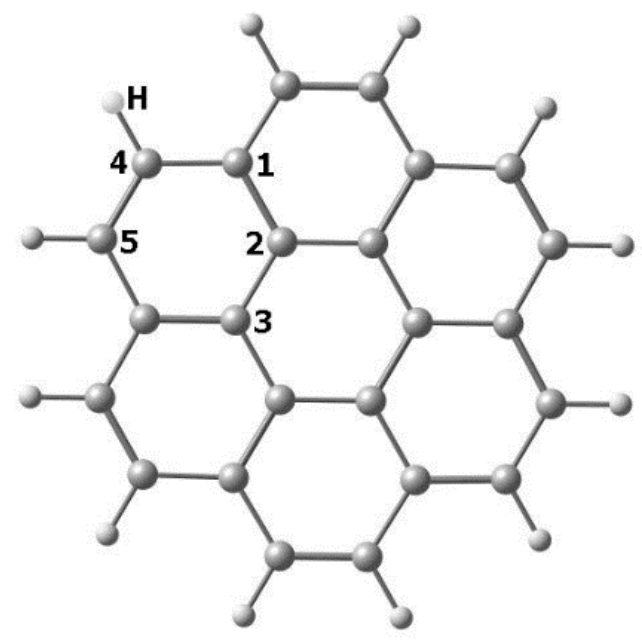

C1-C4 1.423; C1-C2 1.425; C2-C3 1.426; C4-H 1.092

I

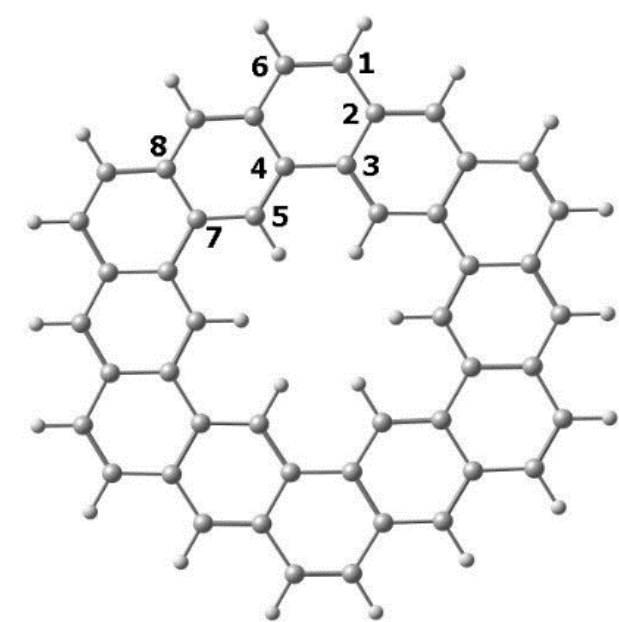

C1-C2 1.439; C1-C6 1.366; C3-C4 1.457; C1-H 1.085

II

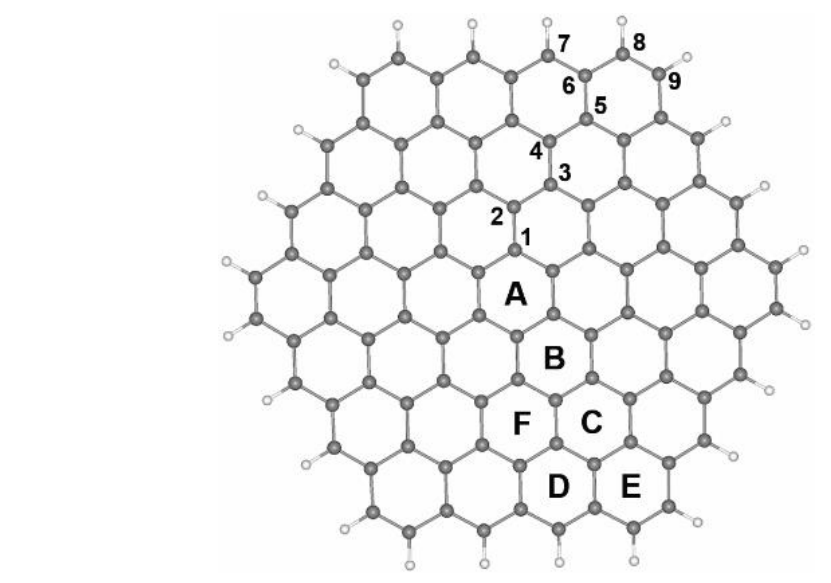

C1-C4 1.422; C2-C3 1.424; C3-C4 1.427; C4-C5 1.423; C5-C6 1.439;

C6-C7 1.394; C6-C8 1.440; C8-C9 1.364; C8-H 1.0924

\section{III}

Fig. 1. Optimized geometries of I (coronene), II (kekulene) and III $\left(\mathrm{C}_{96} \mathrm{H}_{24}\right)$ with selected bond distances $(\AA)$.

\section{Calculation Methods}

The geometries of stable complexes, transition states, and intermediates were optimized at the DFT level, using the PRIRODA-04 program ${ }^{\mathbf{3 6}}$ at the MBC-100k cluster of the Joint Super Computer Center (JSCC) of the Russian Academy of Sciences (Moscow). The nonempirical nonlocal PBE functional ${ }^{37}$ and scalar-relativistic theory were used, together with the L1 extended 
basis set, including Gaussian functions contracted according to the following schemes: $\{2,1\} /\{6,2\}$ for $\mathrm{H}, \quad\{3,2,1\} /\{10,7,3\}$ for $\mathrm{C}$ and $\mathrm{O}, \quad\{6,5,3,1\} /\{19,15,11,5\}$ for $\mathrm{Cr}$, $\{7,6,4,1\} /\{26,23,16,5\}$ for Mo, and $\{8,7,5,2\} /\{30,29,20,14\}$ for $\mathrm{W},{ }^{\mathbf{3 8}, 39}$ for the decomposition of one-electron wave functions to atomic orbitals. Stationary points on the PES were identified by analysis of the Hessians. In addition to the total energy $(E)$ for stationary points on the PES, the thermodynamic functions $(G)$ (free Gibbs energy) at $298.15 \mathrm{~K}$ were calculated by statistical equations of rigid rotator and harmonic oscillator. The correlation of the transition states with the corresponding minima on the PES was checked by the construction of the internal reaction coordinate (IRC). ${ }^{40}$ The scanning procedure over one or several parameters (bond lengths, bond and torsion angles) was used to determine the transition state region. After the structure corresponding to the maximum on the scanning curve was found, the Hessian was calculated for the determination of the vibrational mode corresponding to the process with the further optimization of the saddle point. This procedure is provided in the PRIRODA program. ${ }^{1} \mathrm{H}$ and ${ }^{13} \mathrm{C}$ NMR spectra were calculated with the GIAO (gauge including atomic orbitals) ${ }^{\mathbf{4 1}}$ using L1 full-electron basis set (except for $\mathrm{W}$ ). The calculated chemical shifts are expressed as differences between shielding of tetramethylsilane as a standard and the compound under study. Aromaticities NICS(0)/NICS(1) data were calculated for the center of the corresponding aromatic ring and for the point on the height of $1 \AA$ (Table S4). ${ }^{\mathbf{2}}$ The functional and PBE/L1 basis set were chosen due to systematic studies of the geometry of organometallic compounds and activation barriers of various processes, in particular, IRHR and by comparative calculations in the course of this work.

The interactions between the PAH and $\mathrm{M}(\mathrm{CO})_{3}$ fragments were investigated also within the Morokuma-Ziegler energy decomposition analysis (EDA) framework ${ }^{\mathbf{4 3}, 44}$ through singlepoint calculations with the ADF program ${ }^{45-47}$ on the PRIRODA04-optimized structures, employing the PBE functional, and using the standard TZ2P basis set. ${ }^{48}$ Within the EDA analysis, the total bonding energy (TBE) between two fragments is expressed as the sum of three components, the Pauli (or exchange) repulsion $\left(E_{\text {Pauli }}\right)$, the electrostatic interaction energy $\left(E_{\text {Elstat }}\right)$, and the orbital interaction energy $\left(E_{\text {orb }}\right)$. The $E_{\text {Pauli }}$ destabilizing component complies with the electronic antisymmetry conditions. $E_{\text {Elstat }}$ is the electrostatic energy resulting from the superposition of the unperturbed fragment densities. The $E_{\text {orb }}$ component originates from the relaxation of the molecular system and is associated with the mixing of occupied and unoccupied orbitals, i.e., with covalency. Some ADF single-point test calculations were also performed with different (hybrid) functionals to substantiate the stability of the PRIRODA04-computed activation energies. 


\section{Results and Discussion}

Coronene complexes. The structure of coronene or superbenzene I $\left(\mathrm{C}_{24} \mathrm{H}_{12}\right)$ consists of six fused benzene rings. ${ }^{25}$ It is the smallest reasonable model for graphene. Its optimized geometry as a free ligand (Fig. 1 and Table S1) is in good agreement with previous X-ray ${ }^{\mathbf{4 9 , 5 0}}$ and electron diffraction analyses. ${ }^{\mathbf{5 1 , 5 2}}$ The C-C distances deviate by less than 1-2\% from their experimental counterparts $^{\mathbf{4 9 - 5 2}}$ and are also in a good agreement with previous DFT investigations. ${ }^{\mathbf{5 3 , 5 4}}$ Our computed ${ }^{1} \mathrm{H}$ and ${ }^{13} \mathrm{C}$ NMR chemical shifts are also consistent with previous theoretical data ${ }^{55,56}$ and comparison of them with the experimental NMR and IR vCo data (Tables S3, S4) also confirm the conclusions about the aromaticity of I (see NICS(1) values in Tables S5). Minor deviations of the calculated chemical shifts from the experimental values can be explained by the fact that the DFT calculations were performed for the gas phase, not considering solvent effect (e.g. aromatic solvent induced shift ASIS-effect). ${ }^{57}$

Calculation on the $\mathrm{M}(\mathrm{CO})_{3}(\mathrm{M}=\mathrm{Cr}$, Mo, W) complexes of $\mathbf{I}$ led to two optimized isomers Ia-M and Ib-M (Fig. 2 and Table S6) which differ by the nature of the six-membered ring which is complexed (outer and inner, respectively). They have a nearly planar structure of the ligand and differ significantly in energy (by more than $10 \mathrm{kcal} \mathrm{mol}^{-1}$ ). As expected, complex Ia-M, with the metal coordinated to a more electron-rich peripheral ring, is more stable.
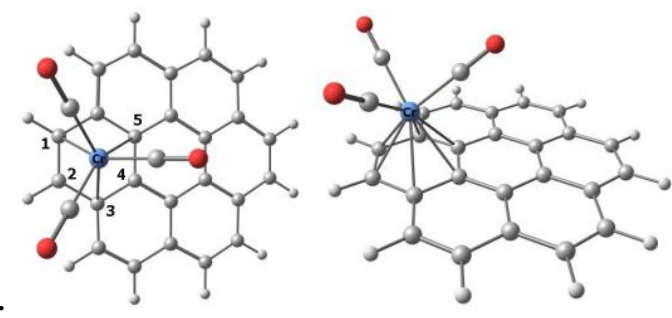

Ia-Cr

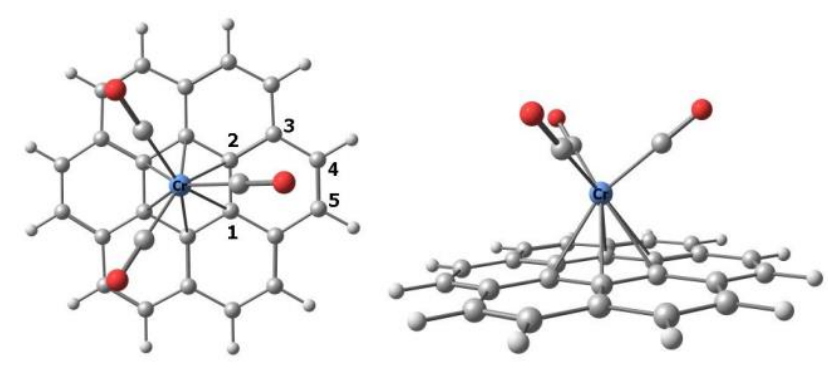

Ib-Cr

Fig. 2. Top and side views of the two isomers of $\mathrm{Cr}(\mathrm{CO})_{3}\left(\eta^{6}\right.$-coronene). 
Thus, Ia-M should be formed predominantly in the course of thermodynamically controlled high temperature synthesis, for example, in the reaction of $\mathbf{I}$ with $\mathrm{M}(\mathrm{CO})_{6}(\mathrm{M}=\mathrm{Cr}$, $\mathrm{Mo}, \mathrm{W})$, in dibutyl ether at $150^{\circ} \mathrm{C}$. This agrees with the experimental data for the aforementioned isoelectronic $\mathrm{RuCp}^{+}$and $\mathrm{FeCp}^{+}$complexes for which the metal coordination to the central ring is not experimentally observed. ${ }^{\mathbf{2 7}, 28}$ The calculated energy difference between $\mathbf{I a - C r}$ and $\mathbf{I b}-\mathbf{C r}$ is high $\left(\Delta \mathrm{G}=12.7 \mathrm{kcal} \mathrm{mol}^{-1}\right)$ and is close to the corresponding value obtained by Türker et al. for Ia-Cr and Ib-Cr $\left(13.2 \mathrm{kcal} \mathrm{mol}^{-1}\right)^{\mathbf{5 8}}$ and Sato et. al. for complexes of $\mathrm{RuCp}^{+}\left(13.52 \mathrm{kcal} \mathrm{mol}^{-1}\right)$ by DFT. ${ }^{59}$

Two types of dynamic behaviors are possible for complexes Ia,b-M ( $\mathbf{M}=\mathrm{Cr}$, Mo, W). One is a degenerate rearrangement Ia-M $\rightleftharpoons$ Ia-M, i.e., a shift of the OMG from one outer sixmembered ring to another outer ring. The other one is the nondegenerate rearrangement Ia$\mathbf{M} \rightleftharpoons \mathbf{I b}-\mathbf{M}$, i.e., the OMG migrates between non-equivalent outer and inner rings. The later process has been studied earlier by $\mathrm{DFT}^{\mathbf{5 9}}$ for the $\mathrm{RuCp}^{+}$complex, and the computed activation barrier from the periphery to the center of coronene in the gas phase turned out to be very high $\left(\sim 40 \mathrm{kcal} \mathrm{mol}^{-1}\right)$. In our $\mathrm{Cr}(\mathrm{CO})_{3}$ complex, the non-degenerate process $\mathbf{I a}-\mathbf{C r} \rightleftharpoons \mathbf{I b}-\mathbf{C r}$ is found to involve no intermediate and proceeds through a single transition state (Scheme 3 and Fig. 3) $\mathbf{T S}(\mathbf{I a}-\mathbf{b})-\mathbf{C r}$ with an activation barrier $\Delta G^{\#}=25.1 \mathrm{kcal} \mathrm{mol}^{-1}$. Hence, the backward process of Scheme 3 has a low activation energy $\Delta G^{\#}=12.4 \mathrm{kcal} \mathrm{mol}^{-1}$, i.e., the process should occur very rapidly at temperatures of kinetic measurements inherent to the $\eta^{6}, \eta^{6}$-IRHR (90$\left.130^{\circ} \mathrm{C}\right)$.
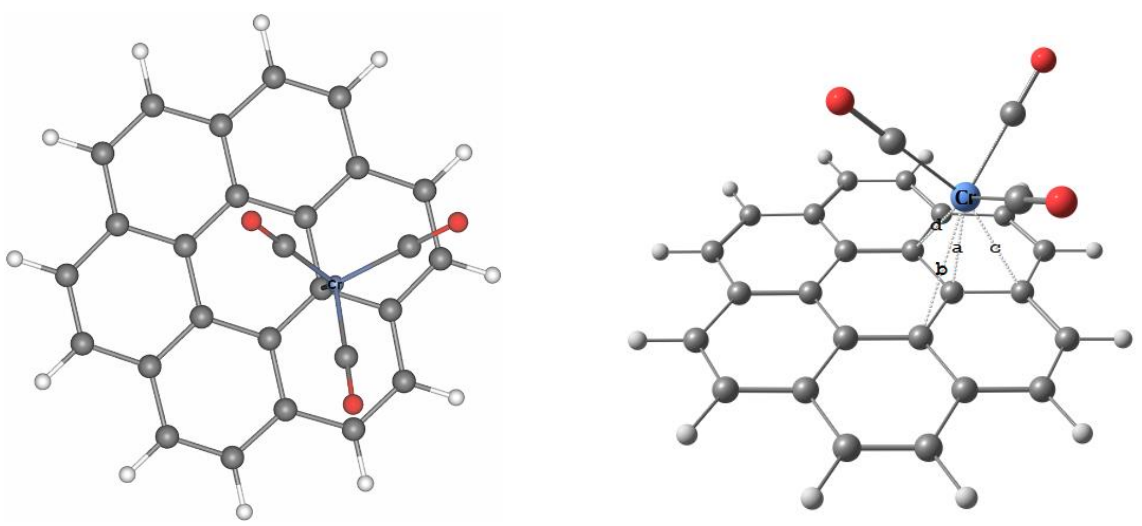

TS(Ia-b)-Cr

Bond lengths $(\AA)$, a-d: $a=2.226 ; b=2.784 ; c=2.599 ; d=2.511$ 


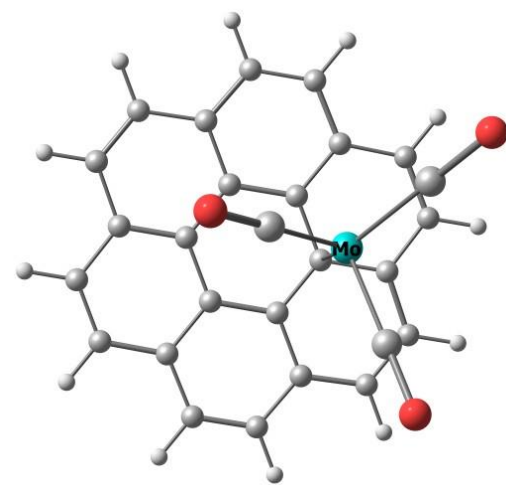

TS(Ia-b)-Mo

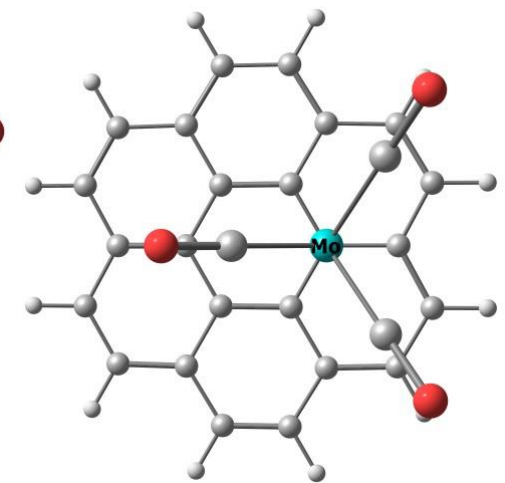

IM(Ia-b)-Mo

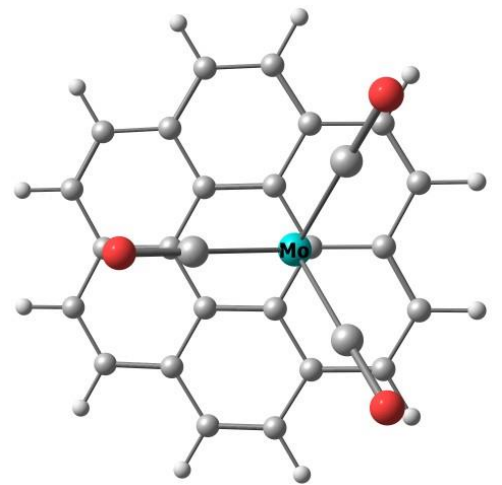

TS' (Ia-b)-Mo

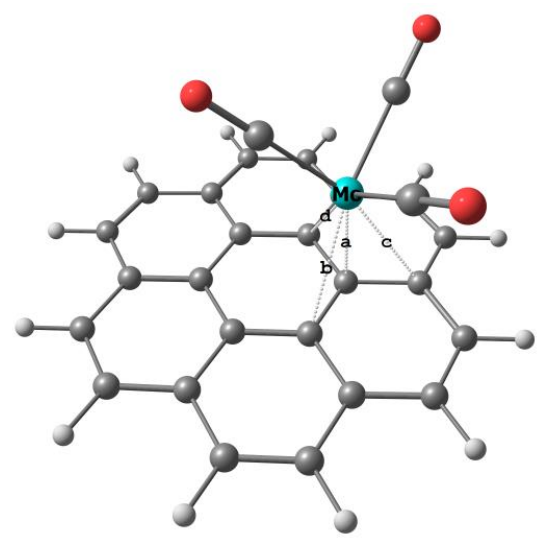

IM(Ia-b)-Mo (side view),

Bond lengths ( $\AA$ ): $a=2.373 ; b=2.735 ; c=2.842 ; d=2.736$ (labelling in IM(Ia-b)-Mo and TS' (Ia-b)-Mo similar to that in TS(Ia-b)-Mo).

Fig. 3. Top and/or side views of the transition states and intermediates involved in the IRHR Ia$\mathbf{M} \rightleftharpoons \mathbf{I b}-\mathbf{M}(\mathbf{M}=\mathrm{Cr}, \mathrm{Mo})$ process. The case of $\mathbf{M}=\mathrm{W}$ (not shown) is similar to that of $\mathbf{M}=$ Mo. All stationary points for all metals are presented in Tables S8-S10. 


$$
\begin{aligned}
& \mathrm{Ia}-\mathrm{Cr} \longrightarrow \mathrm{TS}(\mathrm{Ia}-\mathrm{b})-\mathrm{Cr} \longrightarrow \mathrm{Ib}-\mathrm{Cr} \\
& \Delta \mathrm{G}=0.0 \quad \Delta \mathrm{G}=25.1 \quad \Delta \mathrm{G}=12.7 \\
& \omega=74 . \mathrm{i} \mathrm{cm}^{-1}
\end{aligned}
$$

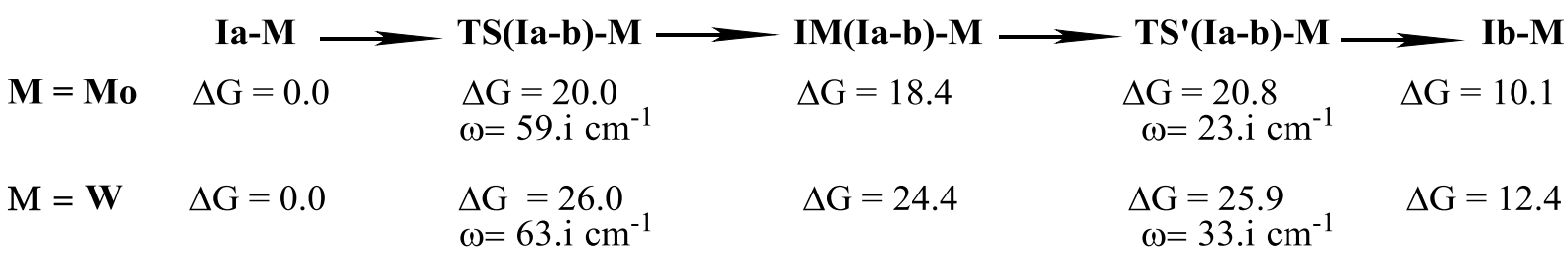

$$
\begin{aligned}
& \begin{array}{cccc} 
& \text { Ia-M } & \text { TS(Ia-a)-M } & \text { Ia-M } \\
\mathbf{M}=\mathbf{C r} & \Delta \mathrm{G}=0.0 & \Delta \mathrm{G}=20.2 & \Delta \mathrm{G}=0.0 \\
& & \omega=72 . \mathrm{i} \mathrm{cm} & \\
\mathbf{M}=\mathbf{M o} & \Delta \mathrm{G}=0.0 & \Delta \mathrm{G}=16.4 & \Delta \mathrm{G}=0.0 \\
& & \omega=64 . \mathrm{i} \mathrm{cm}-1 & \\
\mathbf{M}=\mathbf{W} & \Delta \mathrm{G}=0.0 & & \Delta \mathrm{G}=20.5 \\
& & \omega=75 . \mathrm{cm}^{-1} & \Delta \mathrm{G}=0.0
\end{array}
\end{aligned}
$$

Scheme 3

Unlike in the chromium case, when $\mathbf{M}=$ Mo or $\mathbf{W}$ the $\mathbf{I a - M} \rightleftharpoons \mathbf{I b}-\mathbf{M}$ IRHR proceeds via a slightly different mechanism. It goes through an intermediate IM(Ia-b)-M and via two nearly mirror-symmetric transition states $\mathbf{T S}(\mathbf{I a}-\mathbf{b})-\mathbf{M}$ and $\mathbf{T S} \mathbf{S}^{\prime}(\mathbf{I a}-\mathbf{b})-\mathbf{M}$ both with $\eta^{1}$ hapticity (Scheme 3 and Fig. 3). It is noteworthy that TS(Ia-b)-M, IM(Ia-b)-M and TS' (Ia-b)-M (M = Mo, W) are close in structure and energy. They are also quite close to TS(Ia-b)-Cr. During the whole rearrangement, the $\mathrm{M}(\mathrm{CO})_{3}(\mathrm{M}=\mathrm{Cr}, \mathrm{Mo}, \mathrm{W})$ rotational orientation almost does not change (compare Fig. 2 and 3). It should be noted that in these coronene systems, the rotational energy changes are negligibly low.

The second IRHR process, namely the degenerate $\mathbf{I a - M} \rightleftharpoons$ Ia-M rearrangement between two outer equivalent six-membered rings, proceeds for all metals via the transition state TS(Ia-a)-M without any intermediate formation. With a peripheral $\eta^{3}$ coordination mode of M (Fig. 4), it reminds strongly that computed for the $\eta^{6}, \eta^{6}$-IRHR in naphthalene species. ${ }^{\mathbf{1 0}}$ To summarize, the activation barriers of both degenerate and non-degenerate rearrangements in I-M obey the same trend: $\Delta \mathrm{G}^{\#} \sim 20 \mathrm{kcal} \mathrm{mol}^{-1}$ for both $\mathrm{Cr}$ and $\mathrm{W}$ and a value lower by $\sim 3-5 \mathrm{kcal}$ $\mathrm{mol}^{-1}$ for Mo (Scheme 3). 

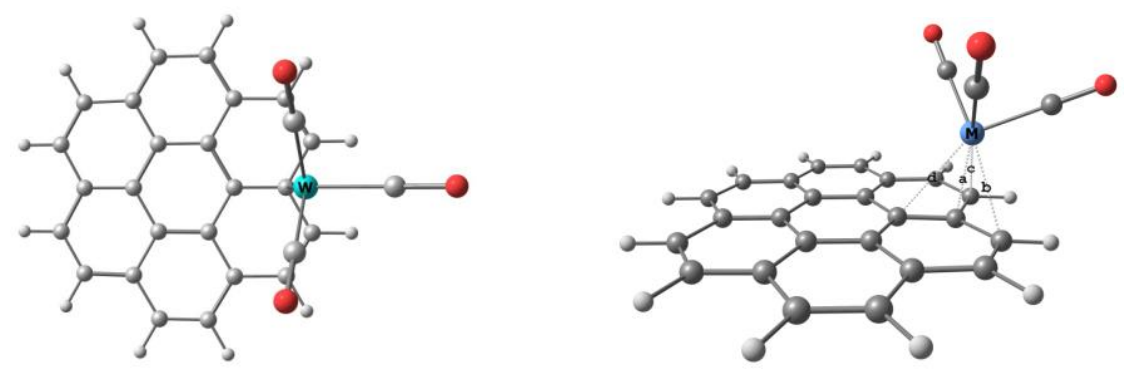

\section{TS(Ia-a)-M}

Bond lengths for TS(Ia-a)-W $(\AA)$ : $a=2.273 ; b=2.605 ; c=2.605 ; d=2.722$ for $W$

Fig. 4. Top and side views of the transition state TS(Ia-a)-W. Similar transition states are found for Cr and Mo (Fig. 4).

In order to get a deeper understanding of the bonding within the stationary points of I-M a Morokuma-Ziegler energy decomposition analysis (EDA) was carried out, considering the interaction between the $\mathrm{PAH}$ and $\mathrm{M}(\mathrm{CO})_{3}$ fragments (see Calculation Methods). The results are exemplified below in the $\mathrm{M}=\mathrm{Cr}$ case. The total bonding energy (TBE) between $\mathbf{I}$ and $\mathrm{Cr}(\mathrm{CO})_{3}$ in the major stationary points is given in Table 1. TBE is expressed as the sum of three components, the Pauli repulsion $\left(E_{\text {Pauli }}\right)$, the electrostatic interaction energy $\left(E_{\text {Elstat }}\right)$, and the orbital interaction energy $\left(E_{o r b}\right)$. The Pauli repulsion decreases with metal connectivity. It is overbalanced by the stabilizing $E_{E l s t a t}$ and $E_{o r b}$ components, of which $E_{o r b}$ is prevailing, indicating covalency predominance. Unsurprizingly, the total bonding energy variation follows that of $\Delta \mathrm{G}$ (Scheme 3). Thus, the highest activation barriers correspond to the less bonding transition state, i.e TS(Ia-b). The particularly small $E_{\text {orb }}$ component in this transition state is associated with low electron transfers between the fragments. In $\mathbf{T S}(\mathbf{I a - b})-\mathbf{C r}$, the electron transfers corresponding to $\mathrm{PAH} \rightarrow$ metal donation and metal $\rightarrow \mathrm{PAH}$ backdonation are 0.32 and 0.20 respectively. For comparison, they are 0.32 and 0.26 in $\mathbf{T S}(\mathbf{I a - a})-\mathbf{C r}$ and 0.88 and 0.65 in Ia-Cr, respectively. 
Table 1. Morokuma-Ziegler energy decomposition analysis (EDA) in stationary points of I-Cr and II-Cr, all values in eV. $E_{\text {Pauli }}=$ Pauli repulsion; $E_{\text {elstat }}=$ electrostatic interaction; $E_{\text {Orb }}=$ orbital interaction. $\mathrm{TBE}=$ total bonding energy $=E_{\text {Pauli }}+E_{\text {elstat }}+E_{\text {orb }}$.

\begin{tabular}{|c|c|c|c|c|c|c|c|c|c|}
\hline & $I-a-C r$ & $T S(I a-b)-C r$ & $T S(I a-a)-C r$ & $I-b-C r$ & $I I-a-C r$ & $T S(I I a-b)-C r$ & $T S^{\prime}(I I a-b)-C r$ & $I M(I I a-b)-C r$ & $I I-b-C r$ \\
\hline$E_{\text {Pauli }}$ & 5.64 & 2.15 & 2.70 & 4.78 & 6.04 & 3.40 & 3.15 & 4.28 & 5.23 \\
\hline $\boldsymbol{E}_{\text {Elstat }}$ & -3.18 & -1.30 & -1.74 & -2.48 & -3.41 & -2.09 & -1.95 & -2.45 & -2.95 \\
\hline$E_{O r b}$ & -4.75 & -1.91 & -2.28 & -4.03 & -5.14 & -2.85 & -2.64 & -3.64 & -4.50 \\
\hline TBE & -2.29 & -1.06 & -1.32 & -1.73 & -2.51 & -1.54 & -1.44 & -1.81 & -2.22 \\
\hline
\end{tabular}

Kekulene complexes. The structure of kekulene II $\left(\mathrm{C}_{48} \mathrm{H}_{24}\right)$ consists of six fused benzene rings. ${ }^{50}$ It constitutes an interesting simple model for perforated graphenes. Its computed structural and spectral parameters (Fig. 1 and Table S2) are in good agreement with previous experimental data. ${ }^{51}$ As for $\mathbf{I}$, two isomers were also found for the $\mathrm{M}(\mathrm{CO})_{3}(\mathrm{M}=$ Cr, Mo, W) complexes of II (Fig. 5). They correspond to the coordination of either the terminal six-membered ring of the phenanthrene-like fragment (IIa-M), or the terminal six-membered ring of the anthracene-like fragment (IIb-M). The former is more stable for all metals (Table S2), but the difference in energy of the isomers is not as high as in the case of Ia,b-M, because the two types of $\mathbf{C}_{6}$ rings in II are chemically quite similar. This means in the course of syntheses both isomers can be formed simultaneously in comparable quantities.

Two possible reaction routes were found for the non-degenerate rearrangement IIa $\rightleftharpoons$ IIb: one of them proceeds through the middle of an inner $\mathrm{C}-\mathrm{C}$ bond, without any exit to the ligand periphery. This pathway is unusual and was not previously observed for similar IRHR. Indeed, it has been established as a rule for a long time ${ }^{\mathbf{6 0}}$ that the IRHR proceeds with a metal shift to the periphery of the ligand but in our case, no migration over the external periphery is observed. In this process, the migration occurs via an $\eta^{4}$-transition state $\mathbf{T S}(\mathbf{I I a}-\mathbf{b})-\mathbf{M}(\mathbf{M}=\mathrm{Cr}$, Mo, W) (Scheme 4 and Fig. 6). No intermediate was observed in the course of the reaction. A minor deviation from planarity of the kekulene cycle can be observed in TS(IIa-b)-M, allowing a weak agostic bonding interaction in this transition state. 

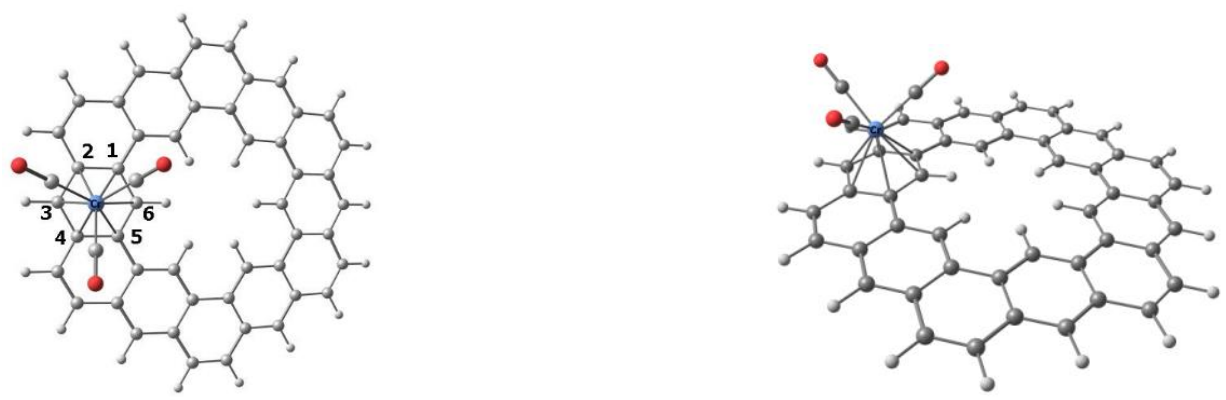

IIa-Cr $\Delta \mathrm{G}=0 \mathrm{kcal} \mathrm{mol}^{-1}$
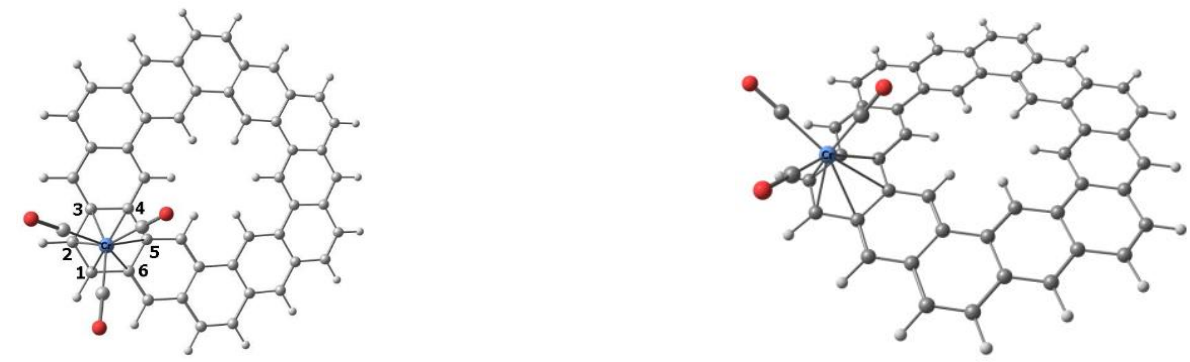

IIb-Cr $\Delta \mathrm{G}=5.9 \mathrm{kcal} \mathrm{mol}^{-1}$

Fig. 5. Top and side views of the two isomers of $\mathrm{Cr}(\mathrm{CO})_{3}\left(\eta^{6}\right.$-kekulene). Similar structures are found for Mo and W (Tables S6 and S7).
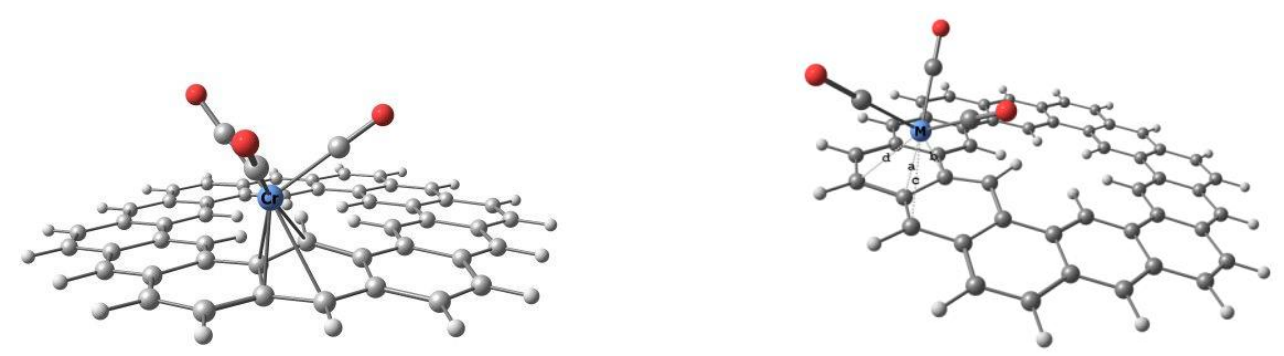

Bond lengths in TS(IIa-b)-Cr $(\AA): \mathrm{a}=2.159 ; \mathrm{b}=2.296 ; \mathrm{c}=2.485 ; \mathrm{d}=2.745$

Fig. 6. Side and top views of the $\eta^{4}$-transition state TS(IIa-b)-M

The other pathway corresponds to a usual metal shift towards the ligand periphery, but that of the ligand internal perimeter. An intermediate is formed, with subsequent migration to the next six-membered ring. In this process, the reaction pathway goes from IIa-M to the transition state $\eta^{2}$-TS'(IIa-b)-M, then the intermediate $\eta^{4}$-IM(IIa-b)-M, the transition state $\eta^{2}$-TS'"(IIa-b)$\mathbf{M}$ and finally IIb-M (Scheme 4 and Fig. 7). Starting from the symmetric intermediate IM(IIab)-M, an alternative route shows up, leading to a degenerate IIa-M isomer through a degenerate TS'(IIa-b)-M transition state. This IIa-M $\rightleftharpoons$ IIa-M rearrangement is analogous to one found earlier by DFT calculations on $\left(\eta^{6}\right.$-phenanthrene $) \mathrm{Cr}(\mathrm{CO}) 3 .{ }^{24}$ It should be noted that $\mathbf{T S}^{\prime}(\mathbf{I I a}-\mathbf{b})-$ $\mathbf{M}$ and TS"(IIa-b)-M have very similar energies for all metals and thus the IRHR energetic 
picture for the degenerate rearrangement IIa-M $\rightleftharpoons$ IIa-M differs negligibly from the undegenerate IIa-M $\rightleftharpoons$ IIb-M. Both IIa $\rightleftharpoons$ IIb IRHR mechanisms have similar activation energy barriers $\Delta \mathrm{G}^{\#} \sim 20-25 \mathrm{kcal} \mathrm{mol}^{-1}$ in the case of $\mathrm{Cr}$ and $\mathrm{W}$ and 4-5 $\mathrm{kcal} \mathrm{mol}^{-1}$ lower in the case of Mo. This trend within the metal triad was already found in the case of the coronene complexes.

\begin{tabular}{|c|c|c|c|c|c|}
\hline & & Non-deg & enerate mech & ms & \\
\hline & & $\mathrm{IIa}-\mathrm{M} \longrightarrow$ & TS(IIa-b)-M - & IIb-M & \\
\hline & $\mathbf{M}=\mathbf{C r}$ & $\Delta \mathrm{G}=0.0$ & $\begin{array}{l}\Delta \mathrm{G}=23.3 \\
\omega=71 . \mathrm{i} \mathrm{cm}^{-1}\end{array}$ & $\Delta \mathrm{G}=5.9$ & \\
\hline & $\mathbf{M}=\mathbf{M o}$ & $\Delta \mathrm{G}=0.0$ & $\begin{array}{l}\Delta \mathrm{G}=17.4 \\
\omega=59 . \mathrm{cm}^{-1}\end{array}$ & $\Delta \mathrm{G}=1.6$ & \\
\hline & $\mathbf{M}=\mathbf{W}$ & $\Delta \mathrm{G}=0.0$ & $\begin{array}{l}\Delta \mathrm{G}=20.4 \\
\omega=52 . \mathrm{i} \mathrm{cm}^{-1}\end{array}$ & $\Delta \mathrm{G}=3.1$ & \\
\hline & $\mathrm{IIa}-\mathrm{M} \longrightarrow$ & - TS'(IIa-b)-M - & $\rightarrow$ IM(IIa-b)- & $\rightarrow$ TS"(IIa-b)-M & - IIb-M \\
\hline $\mathbf{M}=\mathbf{C r}$ & $\Delta \mathrm{G}=0.0$ & $\begin{array}{l}\Delta G=23.8 \\
\omega=90.1 \mathrm{~cm}^{-1}\end{array}$ & $\Delta \mathrm{G}=17.5$ & $\begin{array}{l}\Delta \mathrm{G}=25.1 \\
\omega=111 . \mathrm{i} \mathrm{cm}-1\end{array}$ & $\Delta \mathrm{G}=5.9$ \\
\hline $\mathbf{M}=\mathbf{M o}$ & $\Delta \mathrm{G}=0.0$ & $\begin{array}{l}\Delta G=18.6 \\
\omega=72.1 \mathrm{~cm}^{-1}\end{array}$ & $\Delta \mathrm{G}=12.2$ & $\begin{array}{l}\Delta \mathrm{G}=16.5 \\
\omega=89 . \mathrm{i} \mathrm{cm}^{-1}\end{array}$ & $\Delta \mathrm{G}=1.6$ \\
\hline $\mathbf{M}=\mathbf{W}$ & $\Delta \mathrm{G}=0.0$ & $\begin{array}{l}\Delta \mathrm{G}=22.0 \\
\omega=56.1 \mathrm{~cm}^{-1}\end{array}$ & $\Delta \mathrm{G}=14.9$ & $\begin{array}{l}\Delta \mathrm{G}=21.2 \\
\omega=97 . \mathrm{i} \mathrm{cm}^{-1}\end{array}$ & $\Delta \mathrm{G}=3.1$ \\
\hline
\end{tabular}

Degenerate mechanism

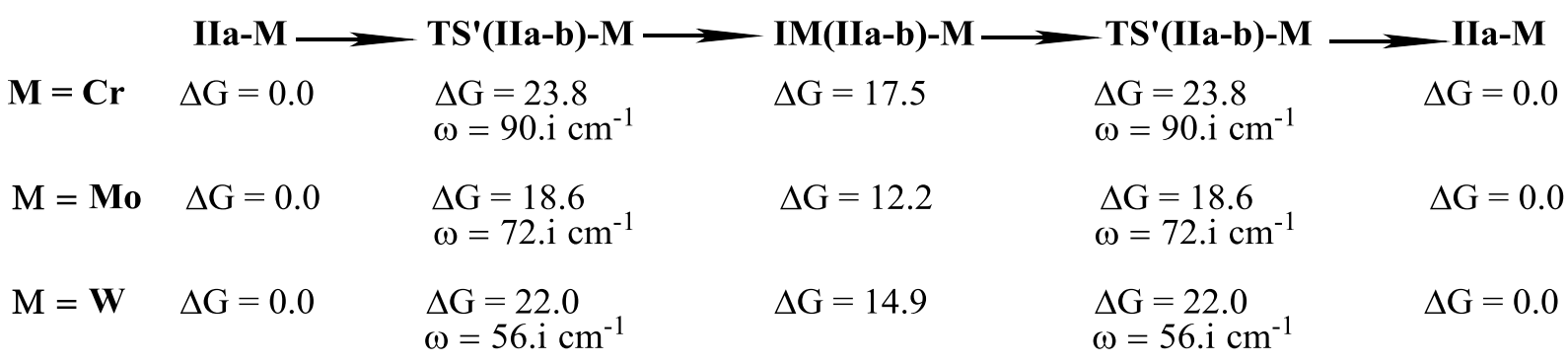

Scheme 4

The EDA analysis of the crucial stationary points in the case of $\mathrm{M}=\mathrm{Cr}$ (Table 1) provides TBE and $E_{\text {orb }}$ values in full agreement with the computed $\Delta \mathrm{G}$ values (Scheme 4 ). They also indicate stronger bonding than in the I-Cr system all along the reaction pathways. 


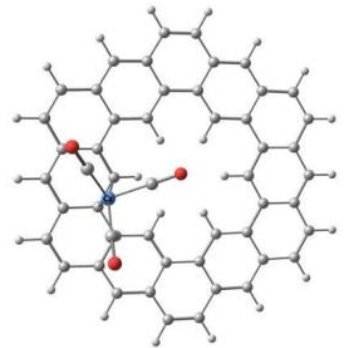

TS'(IIa-b)-M

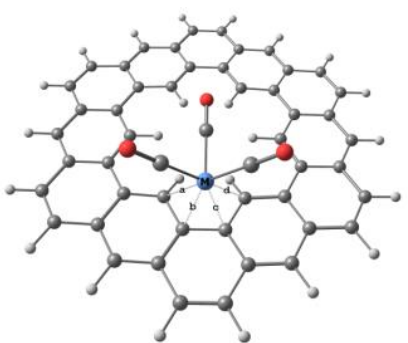

IM(IIa-b)-M

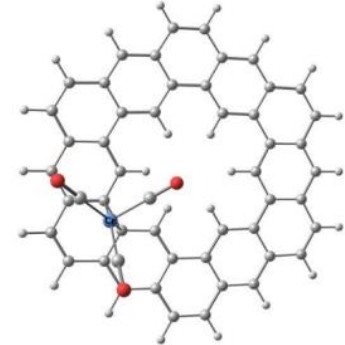

TS"(IIa-b)-M

Bond lengths in IM(IIa-b)-Cr $(\AA): \mathbf{a}=\mathrm{d}=2.456 ; \mathrm{b}=\mathrm{c}=2.420$

Fig. 7. The transition states and inteermediate TS(IIa-b)-M, IM(IIa-b)-M and TS"(IIa-b)-M.

Model graphene complexes. As a reasonably large model for graphene, we chose the $4 \times 4$ structures III ( $\mathrm{C}_{96} \mathrm{H}_{24}$, Fig. 1). ${ }^{\mathbf{1 3}}$ III can be considered as a hexagonal planar molecule with 4ring edges cut out from a sheet of graphene. Our computed structural data on III (Fig. 1 and Table 2) fit very well with neutron diffraction experiments which found the C-C distance to be $1.422 \pm 0.001 \AA^{61}$ Data also agree with previous DFT by Moritz et al. ${ }^{\mathbf{6 2}}$

We now consider complexation of III by $\mathrm{M}(\mathrm{CO})_{3}(\mathrm{M}=\mathrm{Cr}, \mathrm{Mo}, \mathrm{W})$. There are six types of symmetry-equivalent rings available for the OMG coordination (labelled A-F in Fig.1). We investigated complexation of the two extreme positions: that of the central ring A (IIIa-M, Fig. 8a) and that of the more external ring E (IIIe-M, Fig. 8b). IIIe-M was found to be more stable than IIIa-M, consistently with the fact that the preferred localization of an OMG is always on the periphery of the PAH, rather than on an inner position. This is related to the fact that the $\pi$ electron density is larger at the PAH periphery than at its center. The energy difference between both isomers is $\Delta \mathrm{G}=8.3,9.2$ and $10.8 \mathrm{kcal} \mathrm{mol}^{-1}$ for $\mathrm{M}=\mathrm{Cr}$, Mo and $\mathrm{W}$, respectively. Thus one can draw a conclusion that $\mathrm{Cr}(\mathrm{CO})_{3}$ will be more uniformly dispersed on the graphene surface than $\mathrm{Mo}$ and $\mathrm{W}$ because $\Delta \mathrm{G}$ is minimal for $\mathrm{Cr}$.

The general structural features of the computed IIIa-M and IIIe-M isomers (Table. 2), are very similar to that of complexes Ia,b-M and IIa,b-M, and fit well with data from previous experimental and theoretical investigations for tricarbonyl complexes of various PAH. ${ }^{\mathbf{1 0 - 1 4}}$ The only peculiarity of the larger IIIa-M and IIIe-M complexes is that they do not afford any noticeable out-of-plane ligand distortion, in contrast with IIa,b-M. 


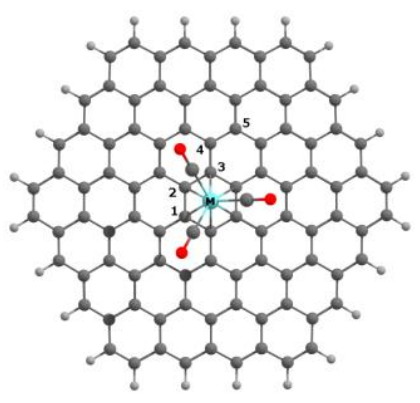

(a)

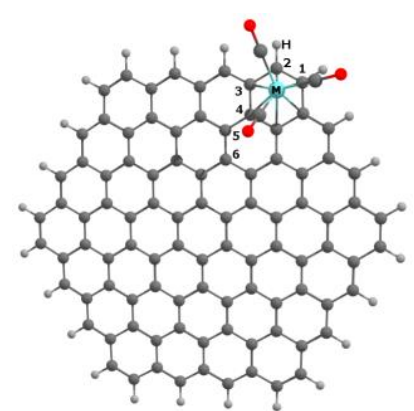

(e)

IIIa-M

IIIe-M

\begin{tabular}{|c|c|c|c|c|}
\hline \multicolumn{2}{|c|}{} & $\mathrm{Cr}$ & Mo & W \\
\hline IIIa & $\Delta \mathrm{E}$ & 7.8 & 8.9 & 9.8 \\
\hline & $\Delta \mathrm{G}$ & 8.3 & 9.2 & 10.8 \\
\hline IIIe & $\Delta \mathrm{E}$ & 0 & 0 & 0 \\
\hline & $\Delta \mathrm{G}$ & 0 & 0 & 0 \\
\hline
\end{tabular}

Fig 8. Optimized geometries of IIIa-Cr and IIIe-Cr and their $\Delta \mathrm{G}$ and $\Delta \mathrm{E}$ values in kcal mol ${ }^{-1}$ The $\mathrm{M}=\mathrm{Cr}$, Mo and $\mathrm{W}$ structures are very similar.

Table 2. Selected bond lenghts $(\AA)$ for the optimized structures IIIa-M и IIIe-M

\begin{tabular}{|l|c|c|c|c|c|c|}
\hline Parameter & \multicolumn{3}{|c|}{ IIIa-M } & \multicolumn{3}{c|}{ IIIe-M } \\
\hline Metal & Cr & Mo & W & Cr & Mo & W \\
\hline M-CO & 1.837 & 1.946 & 1.953 & 1.831 & 1.938 & 1.945 \\
& 2.322 & 2.492 & 2.452 & 2.223 & 2.367 & 2.344 \\
\hline M-C1 & 2.321 & 2.491 & 2.450 & 2.224 & 2.367 & 2.344 \\
\hline M-C2 & 2.322 & 2.493 & 2.452 & 2.368 & 2.531 & 2.498 \\
\hline M-C3 & 1.429 & 1.430 & 1.432 & 1.400 & 1.400 & 1.406 \\
\hline C1-C2 & 1.436 & 1.438 & 1.440 & 1.443 & 1.448 & 1.449 \\
\hline C2-C3 & 1.430 & 1.428 & 1.430 & 1.446 & 1.448 & 1.449 \\
\hline C3-C4 & 1.417 & 1.417 & 1.416 & 1.431 & 1.428 & 1.431 \\
\hline C4-C5 & & & & 1.428 & 1.428 & 1.428 \\
\hline C5-C6 & 120.0 & 120.0 & 120.0 & 121.4 & 121.4 & 121.4 \\
\hline C1-C2-C3 $\left(^{\circ}\right)$ & \multicolumn{3}{|l}{} \\
\hline
\end{tabular}

Graphene is known for its peculiar electronic properties such as electric conductance dealing with very low energy gap width. In Table 3, HOMO-LUMO gaps are presented for the ligands III and I, II (for comparison) and their computed transition metal complexes. 
Table. 3. HOMO-LUMO gaps (in eV) for I, II, III, and their metal tricarbonyl complexes.

\begin{tabular}{|l|l|l|l|l|}
\hline Ligand & Uncomplexed & Cr & Mo & W \\
\hline I & 2.89 & $\begin{array}{l}\text { Ia-M-1.90 } \\
\text { Ib-M-1.54 }\end{array}$ & $\begin{array}{l}\text { Ia-M-1.97 } \\
\text { Ib-M-1.63 }\end{array}$ & $\begin{array}{l}\text { Ia-M-1.92 } \\
\text { Ib-M-1.56 }\end{array}$ \\
\hline II & 2.41 & $\begin{array}{l}\text { IIa-M-1.82 } \\
\text { IIb-M-1.61 }\end{array}$ & $\begin{array}{l}\text { IIa-M-1.77 } \\
\text { IIb-M-1.74 }\end{array}$ & $\begin{array}{l}\text { IIa-M-1.76 } \\
\text { IIb-M-1.66 }\end{array}$ \\
\hline III & 1.37 & $\begin{array}{l}\text { IIIa-M-0.99 } \\
\text { IIIe-M-0.86 }\end{array}$ & $\begin{array}{l}\text { IIIa-M-1.03 } \\
\text { IIIe-M-0.99 }\end{array}$ & $\begin{array}{l}\text { IIIa-M-0.99 } \\
\text { IIIe-M-0.89 }\end{array}$ \\
\hline
\end{tabular}

From the data of Table 3 , it is possible to draw following conclusions, which are important for electronics:

1. Increasing the PAH size leads to a decrease of the HOMO-LUMO gap.

2. Complexation leads to a further decrease of this gap and it is more pronounced for $\mathrm{Cr}$, less pronounced for Mo and intermediate for W.

3. Materials decorated with OMGs will be more conductive when these groups will be localized on edge rather at the PAH center.

For further verification of the structure of graphene tricarbonyl complexes of the chromium triad, their computed IR vCo values are reported in the SI (Table S11). Such data can help in the future to control synthesis and production of such substances in the design of electronic materials and devices, as well as molecular switchers, sensors and machines.

$\eta^{6}, \eta^{6}$-IRHR in metal tricarbonyl complexes of model graphene. The following two principal routes of the $\eta^{6}, \eta^{6}$-IRHR mechanisms in III-M $(\mathrm{M}=\mathrm{Cr}, \mathrm{Mo}, \mathrm{W})$ were considered:

a) A rearrangement consisting of the OMG shift between two inner rings of type $\mathbf{A}$ and $\mathbf{B}$, respectively (IIIa-M $=$ IIIb-M). These two six-membered rings are practically equivalent in our model where they play the role of two neighboring rings in pristine 2D graphene or very large PAH molecule. IIIb-M is thermodynamically slightly preferred over IIIa-M (Scheme 5), owing to the general tendency of the OMG to shift from center to periphery.

b) A similar rearrangement, but involving two outer rings of type $\mathbf{D}$ and $\mathbf{E}$, respectively (IIId-M $\rightleftharpoons$ IIIe-M). These two outer sites can be considered as models for practically equivalent but specific peripheral rings in very huge graphene molecules. This is supported by the very small energy difference between the IIId and IIIe isomers (Scheme 5). 
It should be noted that the unlimited number of inner rings in comparison with the limited number of edge rings in graphene flakes makes the first mechanism much more important for IRHR descriptions in graphene. The IIIa-M $\rightleftharpoons$ IIIb-M $(\mathbf{M}=\mathrm{Cr}, \mathrm{Mo}, \mathrm{W})$ IRHR proceeds through an intermediate IM(IIIa-b)-M and via two practically equivalent transition states TS(IIIa-b)-M and TS'(IIIa-b)-M (Fig. 9, Scheme 5). The IRHR process occurs almost without any $\mathrm{M}(\mathrm{CO})_{3}$ rotation, i.e. no additional energy spent for this motion.

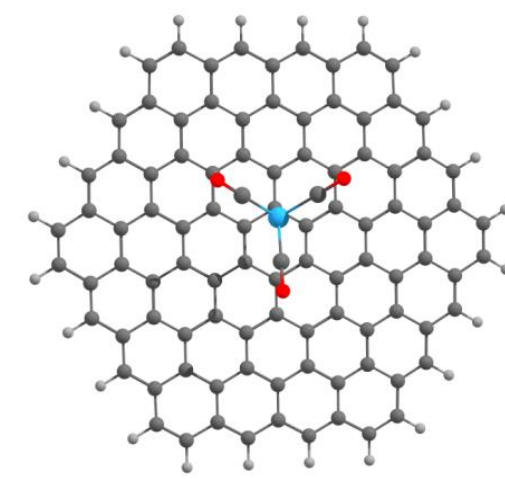

TS(IIIa-b)-M

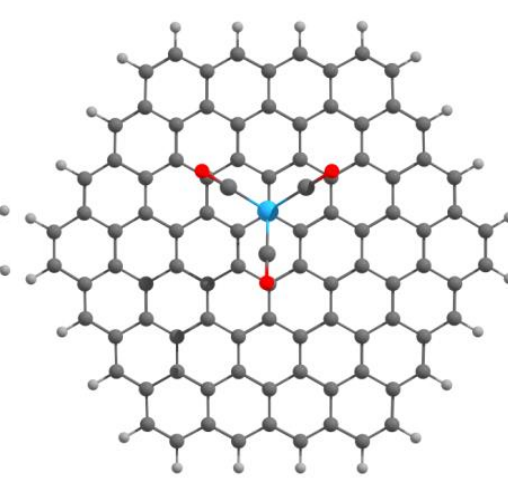

IM(IIIa-b)-M

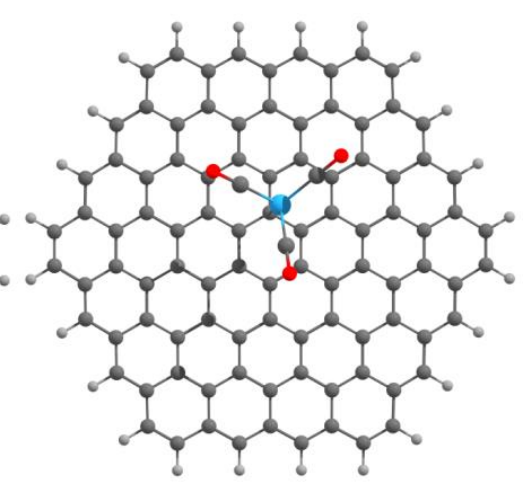

TS'(IIIa-b)-M

Fig. 9. The transition states and intermediates involved in the IIIa-M $\rightleftharpoons$ IIIb-M $(\mathbf{M}=\mathrm{Cr}, \mathrm{Mo}$, W) $\eta^{6}, \eta^{6}-$ IRHR

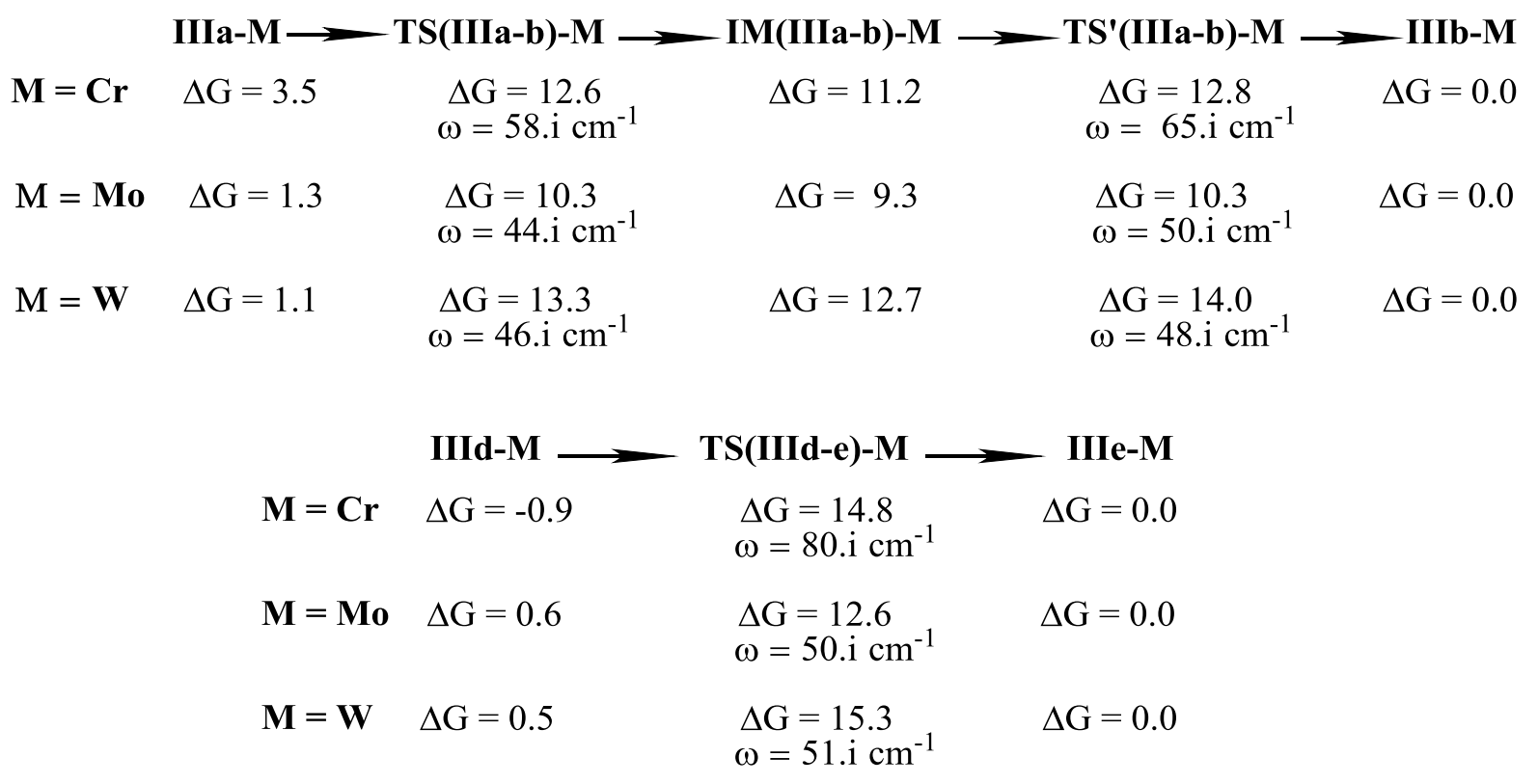

Scheme 5. The stationary points along the IIIa-M $\rightleftharpoons$ IIIb-M and IIId-M $\rightleftharpoons$ IIIe-M $(\mathbf{M}=$ $\mathrm{Cr}, \mathrm{Mo}, \mathrm{W})$ IRHR processes and their relative free energies in $\mathrm{kcal} \mathrm{mol}^{-1}$.

The second (outer) process, namely the IIId-M $\rightleftharpoons$ IIIe-M IRHR, proceeds for the three metals in a single step via TS(IIId-e)-M (Fig. 10 and Scheme 5), and is quite similar to the $\mathbf{I a}-\mathbf{M} \rightleftharpoons$ Ia-M rearrangement in the coronene derivatives. The outer process IIId-M $\rightleftharpoons$ IIIe$\mathbf{M}$ is less favorable than the IIIa-M $\rightleftharpoons$ IIIb-M inner one, as also previously found for the coronene systems. 


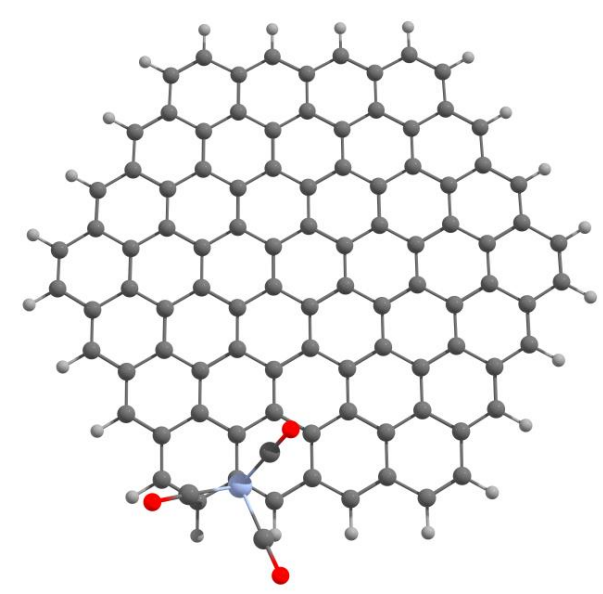

Fig. 10. The transition state TS(IIIe,d)-M, $(M=C r, M o, W)$.

Table 4. Morokuma-Ziegler energy decomposition analysis (EDA) in stationary points of III-Cr, all values in $\mathrm{eV}$. $E_{\text {Pauli }}=$ Pauli repulsion; $E_{\text {elstat }}=$ electrostatic interaction; $E_{\text {Orb }}=$ orbital interaction. $\mathrm{TBE}=$ total bonding energy $=E_{\text {Pauli }}+E_{\text {elstat }}+E_{\text {orb }}$.

\begin{tabular}{c|cccccc}
\hline & IIIa & IM(IIIa-b) & IIIb & IIId & TS(IIId-e $)$ & IIIe \\
\hline $\boldsymbol{E}_{\text {Pauli }}$ & 4.73 & 2.57 & 4.87 & 5.14 & 3.25 & 4.91 \\
$\boldsymbol{E}_{\text {Elstat }}$ & -2.54 & -1.55 & -2.62 & -2.88 & -2.05 & -2.84 \\
$\boldsymbol{E}_{\boldsymbol{O} \boldsymbol{r b}}$ & -3.99 & -2.13 & -4.13 & -4.46 & -2.62 & -4.23 \\
TBE & -1.79 & -1.11 & -1.88 & -2.20 & -1.42 & -2.16 \\
\hline
\end{tabular}

The EDA analysis of the major stationary points in the case of $\mathrm{M}=\mathrm{Cr}$ is given in Table 4. Comparing the TBE values of IIIa-Cr with that of Ib-Cr indicates similar Metal-PAH bonding strength when $\mathrm{Cr}$ binds to the central ring. The the $\mathrm{PAH} \rightarrow$ metal metal $\rightarrow \mathrm{PAH}$ electron transfers of IIIa-Cr (0.72 and 0.54 respectively, are also close to that in $\mathbf{I b - C r}(0.68$ and 0.54 , respectively).The TBE values of the high-energy stationary points IM(IIIa-b) and TS(Ia-b) are also similar. These results suggest that an IRHR process will be easier when occurring in the inner part of a graphene molecule, due to the weaker metal-graphene bonding in the $\eta^{6}$ coordinated energy minima, whereas the bonding within the transition states is less affected by the inner $v s$. outer nature of the process. 
General considerations. Comparing our computed values with related literature data available for $(\mathrm{M}=\mathrm{Cr}, \mathrm{Mo}, \mathrm{W})$ complexes of various PAHs,${ }^{\mathbf{6 - 8 , 2 4}}$ one can conclude that the activation barriers of metallotropic rearrangements decrease with the increasing of PAH size. ${ }^{11-17}$ The available literature data for the most documented chromium tricarbonyl complexes are presented in Table 5.

Moving now down the group 6 column, it appears that all our computed IRHR energy barriers decrease systematically from chromium to molybdenum (up to $5 \mathrm{kcal} \mathrm{mol}^{-1}$ ), then again increase again for tungsten $\left(1-5 \mathrm{kcal} \mathrm{mol}^{-1}\right)$. A similar behavior of the group 8 triad was found earlier for DFT-calculated activation barrier in naphthalene of $\mathrm{MCp}^{+}$complexes $(\mathrm{M}=\mathrm{Fe}, \mathrm{Ru}$, Os). ${ }^{\mathbf{1 8 , 6 3}}$ This dependence can be explained by the fact that when going down the triad, the atomic radius increases, allowing the larger metal to make bonding contacts with more distant atoms in the loosely connected transition states. In the case of the heavier metal, the f-compression effect takes place, thus reducing the above-mentioned atomic radius effect.

Table 5. DFT-computed $\Delta G^{\#}$ activation barriers for $\eta^{6}, \eta^{6}$-IRHR of chromium tricarbonyl complexes of middle-size arenes, graphene* and nanotubes* complexes are presented for comparison.

\begin{tabular}{|l|l|c|l|l|}
\hline & $\begin{array}{l}\Delta \mathrm{G}^{\#} \\
\eta^{6}, \eta^{6} \text {-IRHR }\end{array}$ & $\begin{array}{l}\text { Number of different } \\
\text { mechanisms found } \\
\text { for } \eta^{6}, \eta^{6} \text {-IRHR }\end{array}$ & DFT & References \\
\hline Naphthalene & 30.1 & 2 & B86/SVP & {$[4,15]$} \\
\hline $\begin{array}{l}\text { 1-substituted } \\
\text { naphthalenes }\end{array}$ & $28.9-33.9$ & 2 & PBE/ TZ2P & {$[4,15]$} \\
\hline 2 (4)-NH ${ }_{2}$-byphenyl & $29.9,32.5$ & 1 & PBE/ TZ2P & {$[6]$} \\
\hline Biphenylene & 28.5 & 1 & PBE/ TZ2P & {$[7]$} \\
\hline dibenzothiophene & 31.2 & 1 & PBE/ TZ2P & {$[8]$} \\
\hline Fluoranthene & 31.3 & 2 & PBE/ TZ2P & {$[11]$} \\
\hline Phenanthrene & $29.2,30.6$ & 1 & B86/SVP & {$[24]$} \\
\hline graphene* & 15.4 & 2 & PBE/ TZ2P & {$[13]$} \\
\hline nanotubes* & 16.2 & 1 & PBE/ TZ2P & {$[14]$} \\
\hline
\end{tabular}

Finally, it should be noted that in any of our investigated IRHR processes, the rotation afforded by the $\mathrm{M}(\mathrm{CO})_{3}$ group remains modest, in spite of the fact that the eclipsed $v s$ staggered conformation can change. The rotational energy barriers in the I-M, II-M and III-M isomers being always low, the contribution to the activation barrier of such a small $\mathrm{M}(\mathrm{CO})_{3}$ rotation in the IRHR course is negligible. 


\section{Conclusion}

The structure of the $\mathrm{M}(\mathrm{CO})_{3}(\mathrm{M}=\mathrm{Cr}$, Mo, W) complexes of coronene, kekulene and graphene (I, II and III) were calculated by the DFT method. The structural peculiarities of the stable isomers Ia,b-M, IIa,b-M and IIIa,b/d,e-M are similar for the three metals. The energy and IR vCO, ${ }^{1} \mathrm{H}$ and ${ }^{13} \mathrm{C}$ NMR spectral parameters of these so far uncharacterized complexes were determined. The investigation of the $\eta^{6}, \eta^{6}$-IRHR dynamic process of Ia,b-M, IIa,b-M and IIIa,b/d,e-M, indicates that the corresponding activation barriers decrease when increasing the PAH size. It is due to the fact that the metal-PAH bonding is weaker in the case of the stable minima of large PAH complexes, whereas it remains approximately the same in the transition states and unsaturated intermediates. In the case of complex III-Cr the energy barriers are lower than $\sim 15 \mathrm{kcal} \mathrm{mol}^{-1}$ in comparison with low size PAH. They decrease by $\sim 3-5 \mathrm{kcal} \mathrm{mol}^{-1}$ when going from $\mathrm{Cr}$ to Mo then increases again by $\sim 3-4 \mathrm{kcal} \mathrm{mol}^{-1}$ from Mo to W. Calculations on IIa,b-M strongly suggest that IRHR on perforated graphenes occurs preferentially around the internal rings.

\section{Acknowledgement}

The authors (YFO and IPG) are grateful to the Alexander von Humboldt Foundation (Bonn, Germany) for presenting the working station and auxiliary computer equipment for DFT calculations. Part of this work was done by M. S. Nechaev in the frame of the TIPS RAS Plan.

There are no conflicts of interest to declare. 


\section{References}

1. I.D. Gridnev, O.L. Tok, M. Gielen, R. Willem and B. Wrackmeyer (Eds.), Fluxional Organometallic and Coordination Compounds. Wiley, 2005, 4, 41.

2. C.H. Bartholomew and R.J. Farrauto, in Fundamentals of Industrial Catalytic Processes, Wiley-AIChE; 2 edition, 2006, 996.

3. K. Weissermel and H.-J.Arpe, Industrial Organic Chemistry. Wiley-VCH Verlag GmbH \& Co. KGaA, Weinheim, 2003, 495.

4. Yu.F. Oprunenko, N.G. Akhmedov, D.N. Laikov, S.G. Malyugina, V.I. Mstislavsky, V.A. Roznyatovsky and N.A. Ustynyuk, J. Organomet. Chem., 1999, 583, 136.

5. (a) M. Sodeoka and M. Shibasaki, Synthesis, 1993, 1993, 643; (b) C. Bolm and K. Muñiz, Chem. Soc. Rev., 1999, 28, 51.

6. a) Yu.F. Oprunenko, Russ. Chem. Rev., 2000, 69, 683; (b) C.J. Czerwinski, E.O. Fetisov, I.P. Gloriozov and Yu.F. Oprunenko, Dalton Trans., 2013, 42, 10487.

7. Yu.F. Oprunenko, I.P. Gloriozov, K. E. Lyssenko, S.G. Malyugina, D. Yu. Mityuk, V. I. Mstislavsky, H. Günther, M. Ebener, and G. von Firks, J. Organomet. Chem., 2002, 656, 27.

8. M.V. Zabalov, I.P. Gloriozov, Yu.F. Oprunenko and D.A. Lemenovskii, Russ.Chem. Bull., 2003, 52, 1567.

9. (a) I.D. Gridnev, Coord. Chem. Rev., 2008, 252, 1798; (b) Yu.F. Oprunenko, Doctor of Science (Habilitation) Thesis, Department of Chemistry, M.V. Lomonosov Moscow State University, 1999, Moscow; (c) R.S. Armstrong, M.J. Aroney, C.M. Barnes, K.W. Nugent, Appl. Organomet. Chem., 1990, 4, 569.

10. (a) Yu.F. Oprunenko, S.G. Malugina, Yu.A. Ustynyuk, N.A. Ustynyuk and D.N. Kravtsov, J. Organomet. Chem., 1988, 338, 357; (b) Yu.F. Oprunenko, N.G. Akhmedov, D.N. Laikov, S.G. Malyugina, V.I. Mstislavsky, V.A. Roznyatovsky and N.A. Ustynyuk, J. Organomet. Chem., 1999, 583, 136.

11. I.P. Gloriozov, Yu.F. Oprunenko, Yu. A. Ustynyuk and A.Yu. Vasil'kov, Russ. J. Phys. Chem. A, 2004, 78, 244.

12. (a) J.O.C. Jiménez-Halla, J. Robles and M. Solà, J. Phys.Chem. A, 2008, 112, 1202;

(b) J.O.C. Jiménez-Halla, J. Robles and M. Solà, Organometallics, 2008, 27, 5230.

13. I.P. Gloriozov, R. Marchal, J.-Y. Saillard and Yu.F. Oprunenko, Eur. J. Inorg. Chem., $2015,2,250$. 
14. F. Nunzi, F. Mercuri, F. De Angelis, A. Sgamellotti, N. Re, P. Giannozzi, J. Phys. Chem. $B, 2004,108,5243$.

15. Yu.F. Oprunenko, I.P. Gloriozov, J. Organomet. Chem., 2009, 694, 1195.

16. (a) N.S. Zhulyaev, I.P. Gloriozov, Yu.F. Oprunenko, J.-Y. Saillard, Moscow Univ.

Chem. Bull., 2017, 72, 201; (b) N.S. Zhulyaev, I.P. Gloriozov, Yu.F. Oprunenko and J.Y. Saillard, Russ. Chem. Bull., 2017, 66, 1163.

17. Yu.F. Oprunenko and I.P. Gloriozov, Russ. Chem. Bull., 2011, 60, 213.

18. E.O. Fetisov, I.P. Gloriozov, Yu.F. Oprunenko, J.-Y. Saillard and S. Kahlal, Organometallics, 2013, 32, 3512.

19. P. Hrobárik, V. Hrobáriková, F. Meier, M. Repiský, S. Komorovský and M. Kaupp, M., J. Phys. Chem. A, 2011, 115, 5654.

20. D.L. Bryce, R.E. Wasylishen, Phys. Chem. Chem. Phys., 2002, 4, 3591.

21. B.V. Lokshin, N.E. Borisova, B.M. Senyavin and M.D. Reshetova, Russ.Chem. Bull., 2002, 51, 1656.

22. (a) G. Zhu, J.M. Tanski, D.G. Churchill, K.E. Janak and G. Parkin, J. Am. Chem. Soc., 2002, 124, 13658; (b) G. Zhu, K. Pang, and G. Parkin, J. Am. Chem. Soc., 2008, 130, 1564.

23. E.O Fetisov, I.P. Gloriozov, M.S. Nechaev, S. Kahlal, J.-Y. Saillard, and Yu.F. Oprunenko, J. Organomet. Chem., 2017, 830, 212.

24. A. Pfletschinger and M. Dolg, J. Organomet. Chem., 2009, 694, 3338.

25. (a) H. C. Shen, J. M. Tang, H. K. Chang, C. W. Yang and R. S. Liu, J. Org. Chem., 2005, 70, 10113; (b) Y. Yoshida, K. Isomura, Y. Kumagai, M. Maesato, H. Kishida, M. Mizuno and G. Saito, J. Phys.: Cond. Matt., 2016, 28, 304001.

26. (a) H. Miyoshi, S. Nobusue, A. Shimizu and Y. Tobe, Chem. Soc. Rev., 2015, 44, 6560;

(b) F. Diederich and H.A. Staab, Angew. Chem. Int. Ed. in Eng., 1978, 17, 372.

27. (a) J.W. Buchanan, G.A. Grieves, J.E. Reddic and M.A. Duncan, Int. J. Mass Spect., 1999, 182, 323; (b) M. Lacoste and D. Astruc, J. Chem. Soc., Chem. Comm., 1987, 9, 667.

28. T.J. Seiders, K.K. Baldridge, J.M. O'Connor, J.S. and Siegel, Journal of the American Chemical Society, 1997, 119, 4781.

29. S. Sarkar, S. Niyogi, E. Bekyarova and R.C. Haddon, Chem. Sci., 2011, 2, 1326.

30. S. Sarkar, H. Zhang, J.W. Huang, F. Wang, E. Bekyarova, C.N. Lau and R.C. Haddon, Adv. Mater., 2013, 25, 1131. 
31. (a) E. Bekyarova, S. Sarkar, F. Wang, M.E. Itkis, I. Kalinina, X. Tian and R.C. Haddon, Acc. Chem. Res., 2012, 46, 65; (b) X. Tian, S. Sarkar, M.L. Moser, F. Wang, A. Pekker, E. Bekyarova and R.C. Haddon, Mat. Lett., 2012, 80, 171.

32. (a) G. Zhu, K.E. Janak, J.S. Figueroa and G. Parkin, J. Amer. Chem. Soc., 2006, 128, 5452; (b) E.P. Kündig, C.-H. Fabritius, G. Grossheimann, P. Romanens, H. Butenschön and H.G. Wey, Organometallics, 2004, 23, 3741.

33. A. V. Krasheninnikov and R. M. Nieminen, Theor. Chem. Acc., 2011, 129, 625.

34. R. Zan, U. Bangert, Q. Ramasse and K.S. Novoselov, Nano letters, 2011, 11, 1087.

35. I. Kalinina, E. Bekyarova, S. Sarkar, F. Wang, M.E. Itkis, X. Tian, S. Niyogi, N. Jha and R.C. Haddon, Macromol. Chem. Phys., 2012, 213, 1001; (b) M. Chen, X. Tian, W. Li, E. Bekyarova, G. Li, M. Moser and R.C. Haddon, Chem. Mater., 2016, 28, 2260.

36. D. N. Laikov and Yu. A. Ustynyuk, Russ. Chem. Bull., 2005, 54, 820.

37. J. P. Perdew, K. Burke and M. Ernzerhof, Phys. Rev. Lett., 1996, 77, 3865.

38. K. G. Dyall, J. Chem. Phys., 1994, 100, 2118.

39. D. N. Laikov, Chem. Phys. Lett., 2005, 416, 116.

40. C. Gonzalez and H. B. Schlegel, J. Phys. Chem., 1990, 94, 5523.

41. (a) G. Schreckenbach and T. Ziegler, Int. J. Quant. Chem., 1997, 61, 899; (b) G. Schreckenbach and T. Ziegler, J. Phys.Chem., 1995, 99, 606.

42. Z. Chen, C.S. Wannere, C. Corminboeuf, R. Puchta and P.V.R. Schleyer, Chem. Rev., 2005, 105, 3842.

43. K. Morokuma, J. Chem. Phys., 1971, 55, 1236.

44. T. Ziegler and A. Rauk, Inorg. Chem., 1979, 18, 1558.

45. G. te Velde, F. M. Bickelhaupt, S. J. A. van Gisbergen, C. Fonseca Guerra, E. J. Baerends, J. G. Snijders and T. Ziegler, J. Comput. Chem., 2001, 22, 931.

46. C. Fonseca Guerra, J. G. Snijders, G. te Velde and E. J. Baerends, Theor. Chem. Acc., 1998, 99, 91.

47. ADF2016, SCM, Theoretical Chemistry, Vrije Universiteit, Amsterdam, The Netherlands, http://www.scm.com

48. E. van Lenthe, E.-J. Baerends and J. G. Snijders, J. Chem. Phys., 1994, 101, 9783.

49. (a) J.M. Robertson, and J.G. White, Journal of the Chemical Society (Resumed), 1945, 607-617. (b) H. C. Shen, J. M. Tang, H. K. Chang, C. W. Yang and R. S. Liu, J. Org. Chem., 2005, 70, 10113; (c) Y. Yoshida, K. Isomura, Y. Kumagai, M. Maesato, H. Kishida, M. Mizuno and G. Saito, J. Phys.: Cond. Matt., 2016, 28, 304001.

50. (a) H. Miyoshi, S. Nobusue, A. Shimizu and Y. Tobe, Chem. Soc. Rev., 2015, 44, 6560;

(b) F. Diederich and H.A. Staab, Angew. Chem. Int. Ed. in Eng., 1978, 17, 372; (c) H.A. 
Staab, F. Diederich, C. Krieger, and D. Schweitzer, Chemische Berichte, 1983, 116(10), 3504-3512.

51. H. A. Staab, F. Diederich, C. Krieger and D. Schweitzer, Chem. Ber., 1983, 116, 3504; E. Steiner, L.W. Fowler, P.W. Jenneskens and A. Acocella, Chemical Communications, $2001,7,659$.

52. A. Almenmngen, G. Bastiansen, and F. Dyvik, Acta Crystallographica, 1961, 14, 1056.

53. a) G.R. Jenness, and K.D. Jordan, The Journal of Physical Chemistry C, 2009, 113, 10242; b) H. Jiao, P.V.R. Schleyer, Angew. Chem. Int. Ed.in English, 1996, 35, 2383.

54. a) J. Granatier, P. Lazar, M. Otyepka, and P. Hobza, P. Journal of chemical theory and computation, 2011, 7, 3743-3755; (b) F. De Proft and P. Geerlings, Chem. Rev., 2001, 101, 1451; (c) J. M. Martin, Chem. Phys. Lett., 1996, 262, 97.

55. a) I.P. Gloriozov, M. S. Nechaev, K.V. Zaitsev, Yu.F. Oprunenko, F. Gam, and J.Y. Saillard, Journal of Organometallic Chemistry, 2019, 889, 94; b) A.A. Purwoko, and S. Hadisaputra, Oriental Journal of Chemistry, 2017, 33, 717.

56. a) T. Thonhauser, D. Ceresoli and N. Marzari, Int. J. Quant. Chem., 2009, 109, 3336.

(b) M. Bühl, M. Kaupp, O.L. Malkina and V.G. Malkin, J. Comp. Chem., 1999, 20, 91; (c)

D. Hajgató, M.S. Deleuze and K. Ohno, Chemistry - A European Journal, 2006, 12, 5757;

(c) A. Bagno, Chem. Eur. J. 2001, 7, 1652.

57. N.A. Ustynyuk, L.N. Novikova, V.K. Bel'skii, Yu. F. Oprunenko, S.G. Malyugina, O.I. Trifonova and Yu.A. Ustynyuk, J. Organomet. Chem., 1985, 294, 31.

58. L. Türker and S. Gümüs, Acta Chim. Slov, 2009, 56, 246.

59. H. Sato, H., C. Kikumori, C., and S. Sakaki, S., 2011, Physical Chemistry Chemical Physics, 13(1), 309.

60. T.A. Albright, P. Hofmann, R. Hoffmann, R., C.P. Lillya and P.A. Dobosh, J. Am. Chem. Soc., 1983, 105, 3396.

61. Z. Sofer, P. Šimek, O. Jankovský, D. Sedmidubský, P. Beran and M. Pumera, Nanoscale, 2014, 6, 13082.

62. W. Moritz, B. Wang, M.L. Bocquet, T. Brugger, T. Greber, J. Wintterlin and S. Günther, Phys. Rev. Lett., 2010, 104, 136102.

63. I.P. Gloriozov, M.S. Nechaev, K.V. Zaitsev, Yu.F. Oprunenko, F. Gam and J.-Y. Saillard J. Organomet. Chem. 2019, 889, 9. 